\title{
Key Determinants of Energy Demand: Case of Morocco
}

\author{
Bikrat Fatiha $^{1} \&$ Mohamed Karim ${ }^{1}$ \\ ${ }^{1}$ EREMEPP, University of Mohammed V, Rabat, Morocco \\ Correspondence: Fatiha Bikrat, University of Mohammed V, Rabat, Morocco. E-mail: fati_bik@hotmail.fr
}

Received: February 20, 2019

Accepted: March 26, 2019

Online Published: April 8, 2019

doi:10.5539/ijef.v11n5p50

URL: https://doi.org/10.5539/ijef.v11n5p50

\begin{abstract}
Energy management is a major issue in economic development that goes hand in hand with sustainable development. The objective of this study is to analyze the determinants of energy demand in Morocco during the period 1990-2016. For years to come, energy demand has tended to grow. As a result, it is important to understand the key determinants of energy demand through the analysis of three independent variables: gross domestic product (GDP), access to electricity and direct foreign investment. The approach adopted is to use an Error Correction Vector Model (VECM). Empirical results show that energy demand in Morocco is linked to real causes, which are GDP, access to electricity and foreign direct investment.
\end{abstract}

Keywords: energy, GDP, VECM

\section{Introduction}

The energy situation in Morocco is characterized by a national consumption concentrated around fossil resources. Alongside the weakness of national energy resources, this concentration is combined with dependence on foreign countries for more than $90 \%$.

It should be noted that primary energy demand has increased in recent years by about $5 \%$ on average, driven by the growth of electricity consumption, which has grown on average by $6.5 \%$ per year, due to the almost generalization of rural electrification, but also of the dynamism of the economy and, above all, of the policy of major infrastructure industries, industry, agriculture, social housing, tourism, etc. Faced with this dynamism of the national economy, as well as demographic growth coupled with urbanization and improving of the population's standard of living, according to projections made by the MEMEE, it is expected that primary energy demand will triple and electricity demand will quadruple by 2030, Morocco has been called upon to carry out reforms, in particular as regards to the liberalization of the sector and the mobilization for its energy potential, which could benefit the competitiveness of its economy.

Given the importance of the energy role in economies, several studies have been carried out to apprehend the link between energy consumption and economic growth. These studies adopted several approaches, including short-term and long-term impact analysis and causality analysis between energy consumption and economic growth.

Within this framework, this work is intended to contribute to the existing debate on causal links between energy consumption, economic growth and other variables. In the case of Morocco, as a developing country and importer of almost all its energy, it will provide a better perception of the mechanisms that act on the formation of its energy demand.

As a result, the objective of this study is to empirically identify energy demand variables in Morocco during the period 1990-2016. The choice of this period is justified by the availability of statistical data on variables of the model that we will analyze. The estimation method used is based on the error correction vector model (VECM) which allows for both short and long-term consideration.

To this end, the structure of this article will be distributed as follows: the first section will be devoted to literature review, the second section will include the specification of the model and the methodology for analyzing the relationship between energy demand and its potential determinants and causal links. Finally, the final section, by way of conclusion, will be reserved for the recommendations resulting therefrom.

\section{Literature Review}

Since the industrial revolution that has been an upheaval for the economic world, economists have been 
interested in the link between energy and economic growth in theoretical literature; While several empirical works have been carried out in several countries, especially after the first oil shock in 1973, these studies have shown different results depending on the specific characteristics of each country and the methods used. The first empirical studies of causal relationships between energy demand and GDP were that of (Kraft \& Kraft, 1978), in the US during the period (1947-1974), the results of their studies showed a unidirectional causal relationship of GDP towards energy demand, except that these studies were criticized by (Akarca \& Long, 1980) since the period taken for analysis is unstable. Thus, several approaches have been used to understand the link between energy consumption and economic growth. Some adopted the correlation approach and others in terms of causality, sometimes both. Studying the causal link between energy consumption and economic growth from the causal tests of Engle and Granger, Nachane, Nadkani, and Karnik (1988) highlighted a long-term relationship between energy consumption and economic growth for eleven developing countries and five developed countries. Applying the methodology of Johansen, Masih, and Masih (1996) on a series of articles relating to six Asian countries (India, Pakistan, Indonesia, Malaysia, Singapore and the Philippines), lead to a long-term relationship between energy consumption and GDP in the case of India, Pakistan and Indonesia. With regard to the other three countries (Malaysia, Singapore and the Philippines), the use of an ordinary VAR revealed the lack of a causal relationship between GDP and energy consumption. Ferguson, Wilkinson, and Hill (2000) found that for developed countries there is a correlation between the amount of electricity used and the economic development of 100 countries and find that for the economy as a whole there is a strong correlation between increased energy consumption and increased wealth. But, given that the correlation analysis does not necessarily imply causation, other studies have focused on studying the meaning of causality between electricity consumption and growth (Ghosh, 2002; Shiu \& Lam, 2004).

As part of a multivariate model integrating capital, labor, energy and GDP, for Korea over the period 1970-1999 and with a correction model, (Oh \& Lee, 2004) indicate long-term two-way causality between energy and economic growth., and the short-term unidirectional of energy towards economic growth. Ghali and El-Sakka (2004) also find for Canada a two-way causality between energy consumption and economic growth. On a series of studies conducted in the case of China (Shiu \& Lam, 2004), Wang et al. (2011) concluded that there was one unidirectional causality of energy consumption towards economic growth whereas Zhang and Cheng (2009) found a reverse result. Similarly, for the United States, Bowden and Payne (2009) find a unidirectional causal relationship between energy consumption and economic growth. Ochozias A. Gbaguidi used a correction model to explain the evolution of electricity consumption in ECOWAS countries over the period 1975 to 2005 (Diagne, 2017). Panel data econometrics estimated a regional energy demand function. It has shown that income negatively affects electricity demand. According to this author, a variation on the part of agriculture or industry leads to variation in the same sense of energy demand but on a smaller scale. Ngutsav and Aor (2014) studied the main parameters that determine electricity consumption in Nigeria from 1980 to 2011, four determinants of electricity consumption were used to estimate the exact relationship: real income (proxy per GDP), population, production of the industrial sector and electricity prices. Johansen (1991) test for cointegration was conducted and resulted in a positive long-term relationship between all integrated variables. The Vector Error Correction Model (VECM) was performed to test the dynamics of the short- and long-term model. The results show that all variables play a major role in interpreting electricity consumption in Nigeria, except for electricity prices.

Following the multiple linear regression (MLR) methodology, the study identified six socio-economic factors in its study explaining 99.2\% of local electricity consumption in Nigeria between 1985 and 2005: population density, industrial units, urbanization; employment rate, distance to electricity generation substation and number of households powered by electricity. Opting for a cointegration test proposed by Pesaran, Shin, and Smith (2001) as well as a modified version of the Granger causality test, Wolde-Rufael (2006) analyzed the long-term relationship between per capita electricity consumption and real gross domestic product (GDP) for African countries over the period 1971-2000, empirical results indicate a co-integration relationship between per capita electricity consumption and per capita GDP for only 9 countries. For example, for 5 countries (Republic of Congo, Gabon, Nigeria, South Africa and Zimbabwe), there is a long-term relationship when GDP is taken as a dependent variable, while there is a long-term relationship for 4 countries (Benin, Cameroon, Morocco and Zambia) when per capita electricity consumption has been used as a dependent variable. For 6 countries, it finds one unidirectional causality ranging from GDP to electricity consumption and a contrary result for 3 countries.

Generally, most of these studies indicate that energy demand is closely linked to several variables, including GDP, price, technology, population growth, urbanization, and the more individual countries can have its own distinctive factors that determine its energy demand. 


\section{Empirical Specification and Variables Choice}

The energy demand analysis (an integral part of the demand for goods and services) can provide an understanding of the link between production and consumption and to respond to the problem posed. Based on the literature review, this study holds the main determinants of energy demand in Morocco: GDP, access to electricity and foreign direct investment. Thus, the energy demand equation for Morocco is close to that estimated in several empirical works. It reads as follows:

$$
C E=f(P I B, A C C E L, I E D)
$$

Where:

$\mathrm{CE}$ : the final energy consumption measured in (ktoe), this is the total final energy used locally by all sectors (industrial, residential, etc.),

GDP: gross domestic product measured in (Billions of dollars),

ACCEL: Access to electricity (\% of the population),

IED: Direct foreign investment. Logarithmic transformation is carried out on variables that compress numbers to avoid heterosedasticity problems in statistical analysis, thus achieving effective empirical results and best estimates. The following equation corresponds to the model after logarithmic transformation:

$$
\text { Ln CE }=\alpha+\beta 1 \operatorname{Ln} P I B+\sigma 1 \operatorname{Ln} A C C E L+\varphi 1 \operatorname{Ln} I E D+\varepsilon
$$

Where:

$\varepsilon:$ is the term error; in the time series analysis, it is called white noise, $(\beta, \sigma, \varphi)$ : The long-term coefficients for GDP, ACCEL, and IED are respectively elasticities.

All estimates are made on data covering the period 1990 to 2016 . The period studied was limited by the availability of data. The main sources of our data are :

- Statistics Directorate;

- International Energy Agency;

- World Bank;

- Ministry of Energy.

\section{Results and Interpretation}

\subsection{Graphical Examination}

The graphical analysis of the different variables used in our study shows that the variables have similar trends and are characterized by a general upward trend. This seems to reflect that there is a balanced or a cointegrating relationship between the series.

Ln_IED

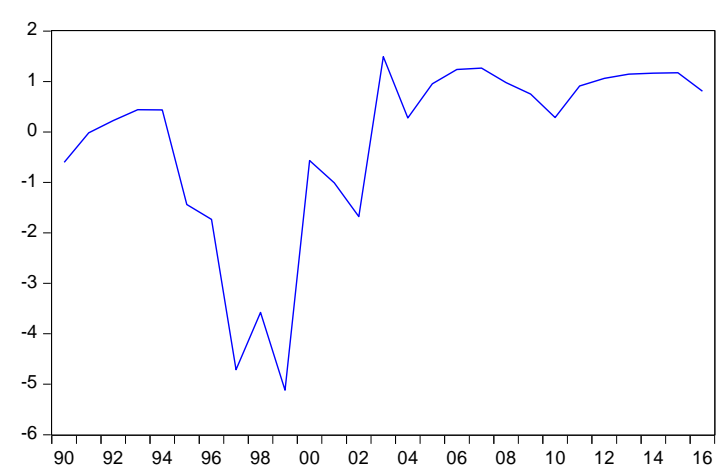

Ln_AccEl

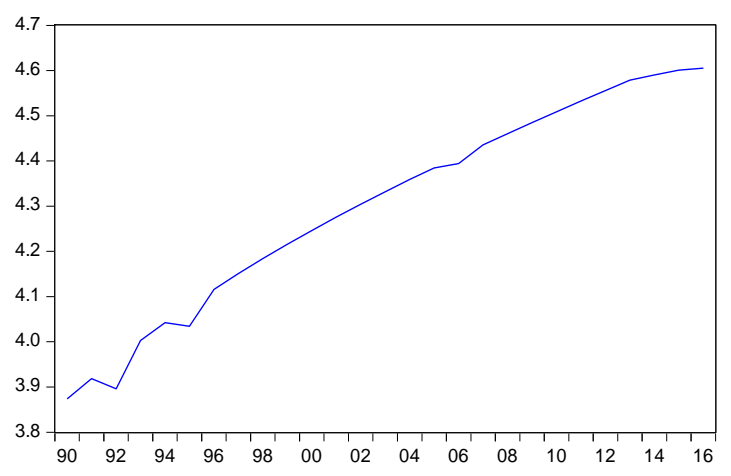


LN_CE

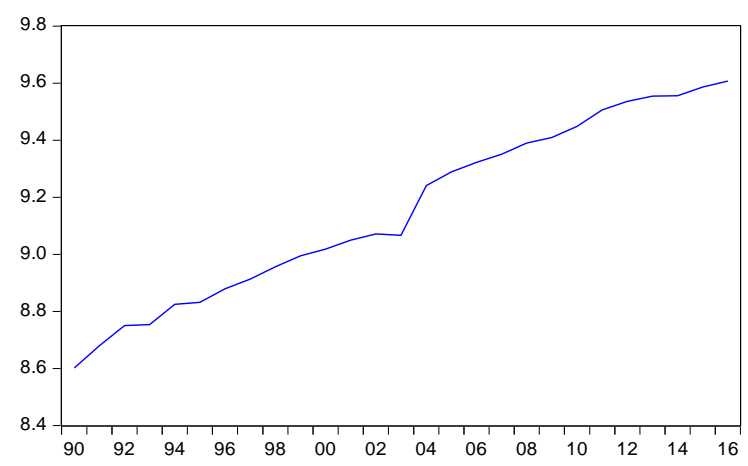

LN_PIB

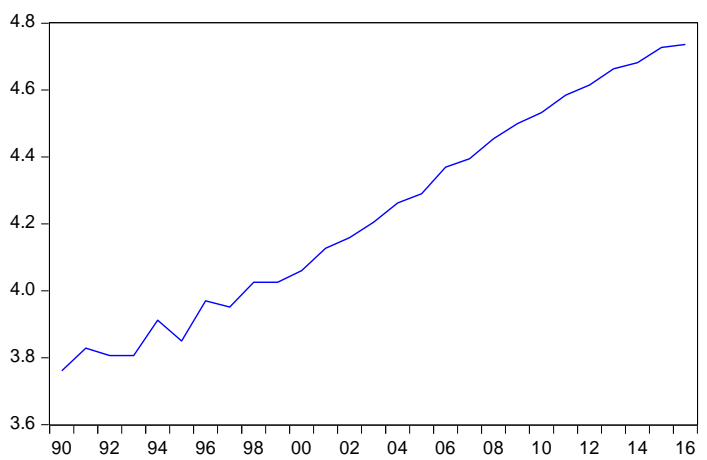

Figure 1. Evolution of the principal variables

The correlation matrix study shows that the series (GDP, IED, ACCEL) are strongly correlated with the CE variable (Table 1), especially GDP for which a correlation coefficient of $99 \%$ was obtained.

Table 1. Correlation matrix

\begin{tabular}{lllll}
\hline & Ln_CE & LN_PIB & Ln_IED & Ln_ACCEL \\
\hline Ln_CE & 1.000000 & 0.991308 & 0.497700 & 0.976799 \\
LN_PIB & 0.991308 & 1.000000 & 0.527690 & 0.964621 \\
Ln_IED & 0.497700 & 0.527690 & 1.000000 & 0.446195 \\
Ln_ACCEL & 0.976799 & 0.964621 & 0.446195 & 1.000000 \\
\hline
\end{tabular}

\subsection{Unit Root Test}

Before making any estimation or modeling, we first need to study the properties of the series by looking to determine whether the series are stationary and what level of integration. To determine the order of integration of the time series, we will use the Dickey Fuller Augmentation (ADF) and Phillips Perron (PP) tests. The application of these tests requires the choice, beforehand, of the number of delays to be introduced as to whiten the residues.

The criteria for AIC, SC, LR and HQ are then used to select the optimal delay (p) in the autoregressive vector (VAR) (Table 2). Four VAR models $(\mathrm{P}=0,1,2,3)$ were estimated for the period 1990-2016. The LR criterion implies a delay of 1 while the FPE, AIC, SC and HQ criteria imply a delay of 2. It is this last criterion which is retained for this study.

Table 2. Statistics and choice criteria for selecting optimal model delay

\begin{tabular}{lcccccc}
\hline Lag & LogL & LR & FPE & AIC & SC & HQ \\
\hline 0 & 50.81934 & - & 0.001187 & -3.901611 & -3.705269 & -3.849522 \\
1 & 53.67531 & $4.521963^{*}$ & 0.001020 & -4.056276 & -3.810848 & -3.991164 \\
2 & 55.43846 & 2.644718 & $0.000962 *$ & $-4.119872 *$ & $-3.825358^{*}$ & $-4.041737^{*}$ \\
3 & 55.70278 & 0.374453 & 0.001029 & -4.058565 & -3.714966 & -3.967408 \\
\hline
\end{tabular}

Note. *indique le retard sélectionné par le critère choisi.

LR: Sequential modified LR test statistic.

FPE: Final prediction error.

AIC: Akaike information criterion.

SC: Schwarz information criterion.

HQ: Hannan-Quinn information criterion. 
Table 3. Results of non-stationary tests

\begin{tabular}{|c|c|c|c|c|}
\hline \multicolumn{5}{|l|}{ Niveau } \\
\hline \multirow{2}{*}{ Variables } & \multicolumn{2}{|c|}{ Augmented Dicker Fuller (ADF) } & \multicolumn{2}{|c|}{ Phillips-Perron $(\mathrm{PP})$} \\
\hline & Intercept & Intercept and trend & intercept & Intercept and trend \\
\hline \multirow{2}{*}{$\mathrm{Ln} \_\mathrm{CE}$} & -0.565110 & -2.300562 & -0.606152 & -2.305422 \\
\hline & $(0.8621)$ & $(0.4190)$ & $(0.8528)$ & $(0.4166)$ \\
\hline \multirow{2}{*}{ Ln_PIB } & 1.118227 & -0.808300 & 0.249088 & -3.750255 \\
\hline & $(0.9965)$ & $(0.95)$ & $(0.9705)$ & $(0.0365)$ \\
\hline \multirow{2}{*}{ Ln_ACCEl } & -1.545071 & -2.847211 & -2.814598 & -2.847211 \\
\hline & $(0.4949)$ & $(0.1945)$ & $(0.0700)^{* * *}$ & $(0.1945)$ \\
\hline \multirow{2}{*}{ Ln_IED } & -2.031675 & -2.440980 & -2.018911 & -2.440961 \\
\hline & $(0.2723)$ & $(0.3519)$ & $(0.2774)$ & $(0.3519)$ \\
\hline \multicolumn{5}{|c|}{ 1ère différence } \\
\hline \multirow{2}{*}{ Variables } & \multicolumn{2}{|c|}{ Augmented Dicker Fuller (ADF) } & \multicolumn{2}{|c|}{ Phillips-Perron $(\mathrm{PP})$} \\
\hline & Intercept & Intercept and trend & intercept & Intercept and trend \\
\hline \multirow{2}{*}{ Ln_CE } & -6.239689 & -6.281031 & -6.191105 & -6.232704 \\
\hline & $(0.0000)^{*}$ & $(0.0001)^{*}$ & $(0.0000)^{*}$ & $(0.0002)^{*}$ \\
\hline \multirow{2}{*}{ Ln_PIB } & -11.93012 & -12.24830 & -11.47752 & -12.21463 \\
\hline & $(0.0000)^{*}$ & $(0.0000)^{*}$ & $(0.0000)^{*}$ & $(0.0000)^{*}$ \\
\hline \multirow{2}{*}{$\mathrm{Ln} \_\mathrm{ACCEl}$} & -8.166790 & -8.353903 & -9.133337 & -23.75306 \\
\hline & $(0.0000)^{*}$ & $(0.0000)^{*}$ & $(0.0000)^{*}$ & $(0.0000)^{*}$ \\
\hline \multirow{2}{*}{ Ln_IED } & -7.108538 & -6.990982 & -6.92192 & -6.827557 \\
\hline & $(0.0000)^{*}$ & $(0.0000)^{*}$ & $(0.0000)^{*}$ & $(0.0000)^{*}$ \\
\hline
\end{tabular}

Note. Numbers in parentheses () are values p. * Asterisk indicates significance at 5\%,** Asterisk indicates significance at $10 \%$. The ADF and PP tests have no single root root. The number of delays is selected automatically according to the Schwarz Info criteria.

The results obtained (Table 3), comparing the values calculated with the critical values for a $5 \%$ significance threshold, show that all series are non-stationary in level but stationary in 1 different difference. Thus, these results allow to test the number of cointegration relationships in the energy demand equation, because all variables have the same integration order (are integrated one I (1)). In addition, the PP test confirms this conclusion by demonstrating the existence of a unit root in the variables.

*Other Variables: total population and the proportion of the urban population relative to the total population and price were eliminated from our study as they do not qualify for the error correction models (ECM).

Also noteworthy is that the Dickey-Fuller test indicate that the breakpoint occurs in 1997 for IED, in 2000 for real GDP, and in 1995 for ACCEL, we find critical economic incidents for Morocco that can match with structural breaks of these series.

First, what causes the break point IED occurred in 1997? Morocco has seen significant growth due largely to the launch of the privatization process and the conversion of foreign debt into investment. However, from 1996 they became characterized by a certain irregularity.

Second, why did the GDP have a structural break in 2000? It is important to highlight at this level the importance of non-irrigated agriculture for Morocco, its vulnerability to climatic conditions, particularly drought, has affected the results of its growth and access to electricity.

\subsection{Cointegration Test}

We remind that, for a long-term relationship to exist between several variables, two conditions must be met. First, the variables must be non-stationary and integrated in the same order. Secondly, their stochastic tendencies must be linked.

The ADF tests therefore suggest that there is a cointegration relationship between energy demand, GDP, access to electricity and foreign direct investment.

To study the existence of a long-term relationship between model variables, we will apply the two following methods:

- The general maximum likelihood method (Johansen, 1988, 1991; Johansen \& Juselius, 1990);

- $\quad$ The two-step method of Engle and Granger (1987). 


\subsubsection{Johansen Cointegration Test}

To ensure the coherence of the study results, two estimates of Johansen cointegration were used: 1 - Trace test ( $\lambda$ - trace), 2- Maximum eigenvalue test $(\lambda$ - max). These results are shown in Table 4 below.

Table 4. Johansen cointegration test

\begin{tabular}{lcccc}
\hline Null hypothesis & Trace tests & $\begin{array}{c}\text { Critical values 95\% } \\
\text { (trace) }\end{array}$ & $\begin{array}{c}\text { Maximum eigenvalue } \\
(\max )\end{array}$ & $\begin{array}{c}\text { Critical value 95\% } \\
(\max )\end{array}$ \\
\hline $\mathrm{r}=0$ & $\begin{array}{l}137.58929 \\
(0.0000)^{* *}\end{array}$ & 47.85613 & $\begin{array}{c}94.10546 \\
(0.0000)^{* *}\end{array}$ & 27.58434 \\
\hline $\mathrm{r} \leq 1$ & $\begin{array}{l}43.47742 \\
(0.0008)^{* *}\end{array}$ & 29.79707 & $\begin{array}{l}25.33022 \\
(0.0121)^{*}\end{array}$ & 21.13162 \\
\hline $\mathrm{r} \leq 2$ & 18.14721 & 15.49471 & $\begin{array}{l}15.47190 \\
(0.0321)^{*}\end{array}$ & 14.26460 \\
\hline $\mathrm{r} \leq 3$ & $(0.0195)^{*}$ & 3.841466 & 2.675311 & 3.841466 \\
\hline
\end{tabular}

Note. Numbers in parentheses () are values p. r. indicates the number of cointegration relationships. ${ }^{*}$ The asterisk indicates significance at the level of $5 \%$; ** Double asterisk indicates significance at $1 \%$.

Trace statistics $(\lambda$ - trace) and maximum value $(\lambda$ - max) reject the null hypothesis of non-Cointegration of $(r=0$ and $r \leq 1)$ at the statistical threshold of $1 \%$, i. e., the lack of cointegration and the existence of a cointegration relationship and more than two co-integration relationships designated by $(\mathrm{r} \leq 2)$ at a level of significance of $5 \%$. Null hypothesis of lack of cointegration is rejected for $r \leq 4$.

Johansen's cointegration tests allow us to conclude that there are three cointegration relationships between the four variables of the model.

\subsubsection{Estimation by Engle and Granger Approach}

The concept of cointegration postulates that if two $\mathrm{X}$ and $\mathrm{Y}$ variables are integrated 1 (I (1)), and if there is a linear combination of these variables that is stationary $\mathrm{I}(0)$, then it can be concluded that $\mathrm{X}$ and $\mathrm{Y}$ are co-integrated (1.1). We have already shown that the series are non-stationary and integrated. We then have to check whether the residues of this linear combination are stationary. Where appropriate, deviations from the equilibrium value tend to cancel over time and, therefore, a long-term relationship exists between the variables. We consider the long-term relationship (Table 5) to be the long-term relationship.

Table 5. Long-term relationship

\begin{tabular}{|c|c|c|c|c|}
\hline Variable & Coefficient & Std. Error & t-Statistic & Prob \\
\hline Ln_PIB & 0.706459 & 0.089929 & 7.855756 & 0.0000 \\
\hline LN_IED & -0.001796 & 0.004730 & -0.379682 & 0.7077 \\
\hline LN_ACCEL & 0.385782 & 0.117161 & 3.292756 & 0.0032 \\
\hline $\mathrm{C}$ & 4.503968 & 0.176027 & 25.58679 & 0.0000 \\
\hline R-squared: 0.988845 & & \multicolumn{3}{|l|}{ Mean dependent var: 9.155148} \\
\hline Adjusted R-squared: 0.987390 & & \multicolumn{3}{|l|}{ D.d. dependent: 0.315738} \\
\hline S.E. of regression: 0.035456 & & \multicolumn{3}{|l|}{ Akaike info criterion: -3.705110} \\
\hline Sum squared resid: 0.028913 & & \multicolumn{3}{|l|}{ Schwarz criterion: -3.513135} \\
\hline Log likelihood: 54.01899 & & \multicolumn{3}{|l|}{ Hannan-Quinn criter: -3.648026 } \\
\hline F-statstic: 679.6131 & & \multicolumn{3}{|l|}{ Durbin-Watson stat: 1.852640} \\
\hline Prob (F-statistic): 0.000000 & & & & \\
\hline
\end{tabular}

It is noted that the Ln_GDP variable is 0.71 and is statistically significant, implying that a $1 \%$ increase in GDP would lead to a $0.71 \%$ increase in energy consumption. Similarly, the long-term elasticity of energy demand (CE) relative to ACCEL is 0.39 and is statistically significant, implying that an increase of $1 \%$ ACCEL would imply a $0.39 \%$ increase in energy consumption. The sign of the coefficient of Ln_ IED is negative but is not significant. This coefficient is equal to -0.0018 suggests that the contribution of IED to energy demand is minimal.

Moreover, the adjustment parameters $\mathrm{R}^{2}$ and $\mathrm{R}^{2}$ adjusted are equal to 0.9888 and 0.9874 respectively, which shows that the model is well adjusted. 


\subsection{Estimation of VECM Model}

Since Johansen's cointegration test rejected the null hypothesis, there should be a long-term relationship in the model. Since all models of the model are non-stationary and cointegrated, the error correction vector model (VECM) could be used to identify the direction of long-term relationships.

\subsubsection{Estimated Long-Term Relationship}

After we have examined the stationarity of the series and the cointegration between variables, we proceed to the estimation stage of the model coefficients, but before proceeding at this stage we have to verify that the unique cointegration relationship is an equation of energy demand and therefore the other variables are weakly exogenous ( $\mathrm{Ln} \mathrm{n}_{-} \mathrm{CE}$ is the endowment) gene, $\mathrm{Ln} \mathrm{n}_{-} \mathrm{GDP}, \mathrm{Ln} \mathrm{n}_{-} \mathrm{IED}$ and $\mathrm{Ln} \mathrm{n}_{-}$ACCEL being like exogenous variables). To this end, we performed a simple exogeneity test based on the estimation of the VECM model using the Johansen method. This test is carried out through the adjustment coefficients associated with the co-integration vector.

Table 6. Estimate of long-term relationship

\begin{tabular}{lccc}
\hline \multirow{2}{*}{ Cointegrating Equation } & \multicolumn{3}{c}{ VECM (Long run relationship) } \\
\cline { 2 - 4 } & Coefficient & Standard error & t-statistics \\
\hline Ln_CE (-1) & 1 & - & - \\
Ln_PIB (-1) & -0.664421 & 0.05509 & -12.0604 \\
Ln_IED (-1) & -0.000461 & 0.00276 & -.016737 \\
Ln_ACCEl (-1) & -0.436444 & 0.07084 & -6.16073 \\
C & -4.467064 & - & - \\
\hline
\end{tabular}

According to the table 6 of VECM, we note that the adjustment parameters associated with the co-integration vector (rate of adjustment) are significant for all variables, so that all variables are weakly exogenous. The coefficients associated with each variable are significantly different from zero statistically. It is noted that an increase of $1 \%$ of GDP, IED, Accel results in an increase of $0.664 \%, 0.0005 \%, 0.436 \%$ respectively.

\subsubsection{Estimation of the Short-Term Relationship}

The error correction mechanism (VECM) is used to test the short-term relationship between variables (Table 7). Results from this table show that the error correction term is a negative and significantly different sign of zero in the energy demand growth relationship, so the EC variable is characterized by the return to the long-term target (towards equilibrium).

Table 7. Estimation of the short-term relationship

\begin{tabular}{lcccc}
\hline Error correction & $\mathrm{D}\left(\mathrm{ln} \_\mathrm{CE}\right)$ & $\mathrm{D}\left(\mathrm{Ln} \_\mathrm{PIB}\right)$ & $\mathrm{D}\left(\mathrm{Ln} \_\mathrm{IED}\right)$ & $\mathrm{D}\left(\mathrm{Ln} \_\mathrm{ACCEL}\right)$ \\
\hline \multirow{3}{*}{ CointEq1 } & -0.741793 & 0.248185 & -14.71907 & 0.889668 \\
& $(0.28321)$ & $(0.25635)$ & $(11.8937)$ & $(0.42353)$ \\
& {$[-2.61900]$} & {$[0.96815]$} & {$[-1.23755]$} & {$[2.10059]$} \\
\hline
\end{tabular}

Note. Numbers in () are standard errors and numbers in [] are t-statistics.

\subsubsection{Validation of VECM Model}

- Diagnostic test

Diagnostic tests were conducted to verify the validity of the model (Table 7) for interpretation.

Table 8. Diagnostic tests

\begin{tabular}{ll}
\hline Tests de diagnostics & Test statistic (Prob. Values) \\
\hline Ljung-Box : Q-Stat & $0.017(0.928)$ \\
Autocorrelation :Test LM & $0.007047(0.9339)$ \\
Normality Test : JB-Test & $0.104162(0.9492)$ \\
Hetero White: Test Chi-sq & $0.895321(0.5977)$ \\
\hline
\end{tabular}

Note. Numbers in parentheses () are values p. * The asterisk indicates significance at the level of $5 \%$.

Table 8 shows that Ljung Box's Q statistic indicates that the residues from each equation are white noises. The Jarque and Bera test allows to accept the null hypothesis (H 0) of error normality. Similarly, the White Attached 
Test indicates that the null hypothesis is accepted, so there is no risk of heterosdasticity. In addition, the LM test does not reveal the existence of error autocorrelation. Thus, the model successfully passes all residual tests. We conclude that the model used in our approach is validated.

- Stability test

To confirm this relationship is broadly stable, several tests may be used: recursive residue tests, square CUSUM and CUSUM. In our case, we opted for CUSUM.

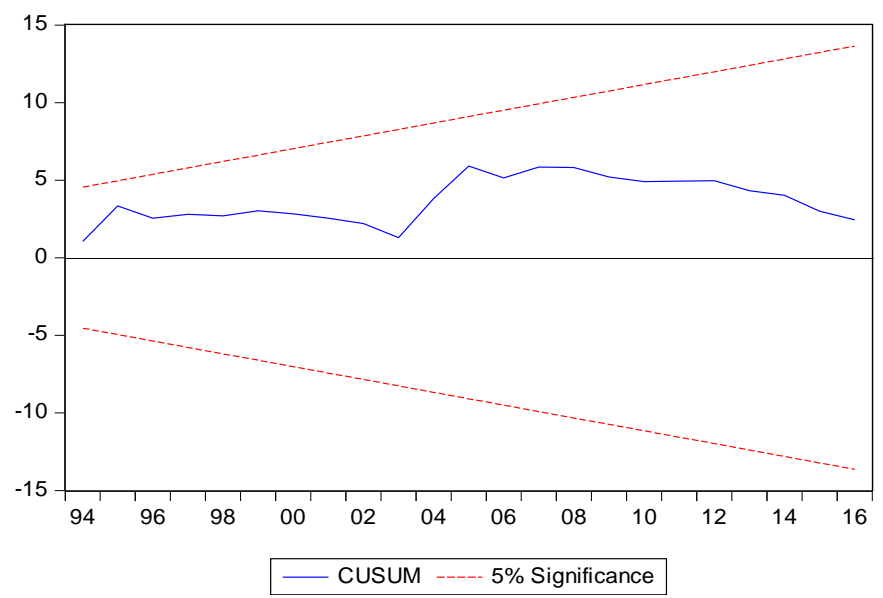

Figure 2. CUSUM test applied to model coefficients

We observe in Figure 2 that CUSUM is within the range of critical values at the threshold of 5\%, implying that the model coefficients are stable.

\section{Conclusion}

This study examined empirically the function of the final energy demand in Morocco for the period 1990-2016, proposing various variables that identify themselves with energy demand.

A multivariate model of time series with three independent variables was developed: GDP, Access to electricity and foreign direct investment.

To ensure consistency of results, two-unit root tests were used to identify the order of integration of all series used in the model. The results of the PP test corroborate the results of ADF, namely that the four variables, including energy demand, are not stationary, while they have become stationary with the first difference.

In order to study the existence of a long-term relationship between model variables, we applied two methods: The general method of maximum likelihood (Johansen, 1988, 1991; Johansen \& Juselius, 1990) and the two-step method of Engle and Granger (1987).The results showed the existence of two cointegration equations in the model at a level of significance of $1 \%$. These cointegration equations stipulate that there are two stable long-term relationships in the model.

The VECM regression was used to clarify the specifications of this relationship with respect to energy demand and its determinants. The VECM has shown that GDP, ACCEL and IED are significantly linked to energy demand.

On the theoretical side, this study contributes to form an idea of the determinants of energy demand in Morocco, which could lead to a more thorough study of the issue.

Also, access to electricity and foreign direct investment were implicated in the model. These factors had not yet been considered in similar studies on energy demand in Morocco.

Another important conclusion was noted that the variables involved explain energy demand, in other words, more GDP, ACCEL and IED growth leads to increased energy demand. This means that an energy policy focusing on energy management and renewable energy may be put in place without any negative effects on economic growth. This conclusion is also consistent with the objectives set by national strategies.

\section{References}

Akarca, A. T., \& Long, T. V. (1980). On the Relationship Between Energy and GNP: A Reexamination. The 
Journal of Energy and Development, 5(2), 326-331. Retrieved from http://www.jstor.org/stable/24806899

Bowden, N., \& Payne, J. E. (2009). The causal relationship between U. S. energy consumption and real output: A disaggregated analysis. Energy Sources Part B Economics Planning \& Policy, 31, 180-188. https://doi.org/10.1016/j.jpolmod.2008.09.001

Diagne, A. (2017). Modélisation économétrique de la consommation d'électricité au Sénégal de 1999 à 2015. Retrieved from https://hal.archives-ouvertes.fr/hal-01473458

Engle, R. F., \& Granger, C. W. J. (1987). Co-integration and error correction: Representation, estimation, and testing. Econometrica: Journal of the Econometric Society, 251-276. https://doi.org/10.2307/1913236

Ferguson, R., Wilkinson, W., \& Hill, R. (2000). Electricity use and economic development. Energy Policy, 28(13), 923-934. https://doi.org/10.1016/S0301-4215(00)00081-1

Ghosh, S. (2002). Electricity consumption and economic growth in India. Energy Policy, 30(2), 125-129. https://doi.org/10.1016/S0301-4215(01)00078-7

H. Ghali, K., \& I. T. El-Sakka, M. (2004). Energy use and output growth in Canada: A multivariate cointegration analysis. Energy Economics, 26. https://doi.org/10.1016/S0140-9883(03)00056-2

Johansen, S. (1988). Statistical analysis of cointegration vectors. Journal of Economic Dynamics and Control, 12(2-3), 231-254. https://doi.org/10.1016/0165-1889(88)90041-3

Johansen, S. (1991). Estimation and Hypothesis Testing of Cointegration Vectors in Gaussian Vector Autoregressive Models. Econometrica, 59(6), 1551-1580. https://doi.org/10.2307/2938278

Johansen, S., \& Juselius, K. (1990). Maximum likelihood estimation and inference on cointegration-with applications to the demand for money. Oxford Bulletin of Economics and Statistics, 52(2), 169-210. https://doi.org/10.1111/j.1468-0084.1990.mp52002003.x

Kraft, J., \& Kraft, A. (1978). On the Relationship Between Energy On the Relationship Between Energy and GNP. Source: The Journal of Energy and Development.

Masih, A. M. M., \& Masih, R. (1996). Energy consumption, real income and temporal causality: Results from a multi-country study based on cointegration and error-correction modelling techniques. Energy Economics, 18(3), 165-183. https://doi.org/10.1016/0140-9883(96)00009-6

Nachane, D. M., Nadkarni, R. M., \& Karnik, A. V. (1988). Co-Integration and Causality Testing of the EnergyGDP Relationship: A Cross-Country Study. Applied Economics, 20(11), 1511-1531. https://doi.org/10.1080/00036848800000083

Ngutsav, A., \& Aor, R. (2014). Analysis of Determinants of Electricity Consumption in Nigeria. The Nigerian Journal for Energy and Environmental Economics, 6(1).

Oh, W., \& Lee, K. (2004). Energy consumption and economic growth in Korea: testing the causality relation. Journal of Policy Modeling, 26(8-9), 973-981. https://doi.org/10.1016/J.JPOLMOD.2004.06.003

Pesaran, M. H., Shin, Y., \& Smith, R. J. (2001). Bounds testing approaches to the analysis of level relationships. Journal of Applied Econometrics, 16(3), 289-326. https://doi.org/10.1002/jae.616

Shiu, A., \& Lam, P. (2004). Electricity consumption and economic growth in China. Energy Policy, 32, 47-49. https://doi.org/10.1016/S0301-4215(02)00250-1

Wang, Y., Wang, Y., Zhou, J., Zhu, X., \& Lu, G. (2011). Energy consumption and economic growth in China: A multivariate causality test. Energy Policy, 39(7), 4399-4406. https://doi.org/10.1016/j.enpol.2011.04.063

Wolde-Rufael, Y. (2006). Electricity Consumption and Economic Growth: A Time Series Experience for 17 African Countries. Energy Policy, 34. https://doi.org/10.1016/j.enpol.2004.10.008

Zhang, X., \& Cheng, X. (2009). Energy consumption, carbon emissions, and economic growth in China. Ecological Economics, 68, 2706-2708. https://doi.org/10.1016/j.ecolecon.2009.05.011

\section{Copyrights}

Copyright for this article is retained by the author(s), with first publication rights granted to the journal.

This is an open-access article distributed under the terms and conditions of the Creative Commons Attribution license (http://creativecommons.org/licenses/by/4.0/). 